\title{
Why knee ligament registries are important...
}

\author{
Lars Engebretsen · Magnus Forssblad
}

Published online: 2 December 2008

(C) Springer-Verlag 2008

National quality registries have been used in several medical specialties to improve health care in Scandinavia [1, 3-6]. Due to the inferior clinical results associated with some hip prosthesis designs in the early 1980s [6], the nationwide Hip Arthroplasty Register (NAR) was established in Sweden in 1979 and in Norway in 1987 with implant revision as the main end point [1]. The purpose is the early detection of inferior results caused by implants, cements or surgical techniques [1, 3, 6]. In 1994, the Norwegian registry was expanded to include all joint replacements [3]. In 1995, two studies were published [1, 3] describing the detection of inferior implants at an early stage, a finding only possible through registry studies.

NAR is based on a simple reporting system (approximately $1 \mathrm{~min}$ to complete a single-paged registration form), and the hospitals are provided with continuous feedback from the registry [1, 2]. These two factors are believed to explain why the compliance rate of nearly $100 \%$ has not declined during 20 years of operation $[1,2]$. Immediately after each operation, the surgeon completes the registration form, which is mailed to the NAR office. Patient identification and the different procedures, including the type of implant and cement used, are specified on

L. Engebretsen $(\bowtie)$

Orthopaedic Center, Ullevål University Hospital and Faculty of Medicine, University of Oslo and Oslo Sports Trauma Research Center, Sognsveien 220, Ullevaal Stadion, PB 4014, 0806 Oslo, Norway

e-mail: lars.engebretsen@medisin.uio.no

M. Forssblad

Capio Artro Clinic AB and Stockholm Sports Trauma

Research Center, Sophiahemmet, Valhallavägen 91,

11427 Stockholm, Sweden

e-mail: magnus.forssblad@capio.se the registration form. Feedback is given as annual national reports. In addition, each hospital receives a report on its own activities and results, which can be compared to the national average. A wide range of studies have been published based on the NAR database [1, 3, 6].

In contrast to joint replacement surgery, where national registries have been established in Norway, Sweden (1979), Finland (1980), Denmark (1995), Australia (1999), New Zealand (1999), Canada (2000), Romania (2001), and England and Wales (2003), no prospective surveillance system has existed for monitoring the outcome of knee ligament surgery in a predefined population. Evidence from the Scandinavian joint replacement registries indicates that a national knee ligament registry could be highly beneficial. First, treatment outcome can be improved through feedback to the hospitals and surgeons from the registries. Second, there are still several unresolved issues related to cruciate ligament surgery and postoperative rehabilitation methods. Some of these can and should be addressed by conducting properly designed randomized controlled trials (RCTs). However, because of practical, financial or other restraints, such studies are often not possible. Also, some questions can only be answered by large cohort studies. This can include the detection of procedures and devices that result in premature failure. Third, a large cohort study can be used to identify prognostic factors associated with good and poor outcomes. Data from the Norwegian Registry show a very high compliance rate [2] and also that this type of registry can be run in a country with 5 million inhabitants for approximately US\$100,000 a year excluding the local costs.

With this background, the Norwegian Knee Ligament Registry (NKLR) was started in June 2004, followed by the Danish and Swedish registries in 2005. In this edition of the KSSTA journal, Martin Lind and co-workers report from 
the Danish registry, its design, procedures and characteristics of patients included. The results show that in 30 months of operation, $85 \%$ of all patients undergoing cruciate ligament surgery were included in the registry. Already more than 5,000 ligament reconstructions are in the database. Seventeen percent had additional cartilage injuries. Three percent underwent revision during the first 2 postoperative years. Based on these data, it may be expected that the registries in the Nordic Countries each year will enroll approximately 6-7,000 primary ACL reconstruction cases. Because the forms and analyses are done in cooperation, this will be a substantial database in the coming years. In the future, the registry will also record revision reconstruction surgery and other surgical procedures for all knee joints previously recorded in the registry.

Patient registries are established to improve the standard of health care and should be used in as many countries as possible. One vision is to have a common international registry for knee ligament surgery supported by, for example, ESSKA and ISAKOS. For countries that need a separate database for legal reasons, the software could be the same for all countries. In a very short time, a huge amount of data could be obtained, and fruitful international comparisons would be possible.

Specifically, registries are meant to serve three specific purposes: to improve treatment outcomes through feedback to the hospitals and surgeons, to detect procedures and devices that result in premature failure and to identify prognostic factors associated with good and poor outcomes. However, to serve these purposes, the accuracy of the outcome measures used is critical. The arthroplasty registries only use revision surgery as an end point. Thus, patients may have a poor result without this being registered. In contrast, in addition to revision surgery, the knee ligament registries therefore also include routine followups with patient-reported KOOS scores. KOOS scores are collected preoperatively from the patients, as well as after 2, 5 and 10 years. The intention is to detect inferior results and early failures, regardless if patients with a failed graft decide to go through revision surgery or not. Also, at a later stage, data from NKLR can be combined with data from registries on knee arthroplasties, thus using surgically verified severe osteoarthritis as an additional end point. We predict that these registries will play a major role in the future!

\section{References}

1. Espehaug B, Furnes O, Havelin LI, Engesaeter LB, Vollset SE, Kindseth O (2006) Registration completeness in the Norwegian Arthroplasty Register. Acta Orthop 77:49-56

2. Granan LP, Bahr R, Steindal K, Furnes O, Engebretsen L (2008) Development of a national cruciate ligament surgery registry: the Norwegian National Knee Ligament Registry. Am J Sports Med 36:308-315

3. Havelin LI, Engesaeter LB, Espehaug B, Furnes O, Lie SA, Vollset SE (2000) The Norwegian Arthroplasty Register: 11 years and 73, 000 arthroplasties. Acta Orthop Scand 71:337-353

4. Irgens LM (2000) The Medical Birth Registry of Norway. Epidemiological research and surveillance throughout 30 years. Acta Obstet Gynecol Scand 79:435-439

5. Lichtenstein P, De Faire U, Floderus B, Svartengren M, Svedberg P, Pedersen NL (2002) The Swedish Twin Registry: a unique resource for clinical, epidemiological and genetic studies. J Intern Med 252:184-205

6. Malchau H, Herberts P, Eisler T, Garellick G, Söderman P (2002) The Swedish Total Hip Replacement Register. J Bone Joint Surg 84-A(Suppl 2):2-20

7. Sokka T (2004) National databases and rheumatology research I: longitudinal databases in Scandinavia. Rheum Dis Clin North Am 30:851-867 